\title{
Editorial
}

\section{AAC - Atividades acadêmicas complementares}

\section{Prof. Dr. Antonio Carlos Hernandes ${ }^{1}$ Prof. Dr. Edmund C. Baracat ${ }^{2}$}

O objetivo das atividades acadêmicas complementares (ACC) é enriquecer o processo de ensino-aprendizagem, complementando a formação profissional, social e cultural do estudante.

Este conjunto de atividades tem como característica principal a flexibilidade de carga horária semanal, com controle do tempo total de dedicação do estudante durante o semestre ou ano letivo.

Essas atividades devem ser realizadas ao longo da graduação e podem ser cursadas de acordo com o interesse ou a afinidade do estudante.

Elas abrangem as áreas de Ensino e Formação Sociocultural, Responsabilidade Social e Interesse Coletivo, Pesquisa e Formação Profissional e Extensão e Aperfeiçoamento.

Como exemplos de AAC para discentes podemos citar: atividades de cultura e extensão, bolsas diversas, cooperativas estudantis, cursos extracurriculares EAD, empresa júnior, iniciação científica, participação como aluno ouvinte (dos programas de pós-graduação), participação em atividades na agência USP de inovação, participação em visitas monitoradas na unidade, participação em eventos, organização de eventos, Projeto Rondon, representação discente em colegiados, semanas acadêmicas, visitas técnicas, atividades esportivas, participação em congressos, seminários, palestras e conferências, cursos de difusão/atualização, disciplinas cursadas no exterior/intercâmbios, estágios não obrigatórios, monitoria, participação em concursos e premiações, participação em ligas e em grupos científicos, participações em grupos e organizações que promovam ações sociais, programas de extensão de serviços à comunidade, publicações, representação em entidades estudantis e treinamentos técnicos.

Além das AAC discentes, há também as atividades docentes, como: orientação de iniciação à pesquisa científica, supervisão de seminários, supervisão de atividades acadêmico-científico-culturais, aulas teórico-práticas em horários variáveis, viagens didáticas, orientação de trabalhos de conclusão, supervisão de estágios, supervisão de trabalho de campo, coordenação de turmas de disciplinas e tutoria acadêmica.

Destacamos aqui como exemplos de AAC o Projeto Bandeira Científica, o Mentoring e as Ligas Acadêmicas.

O Projeto Bandeira Científica foi idealizado no início da década de 1950 por acadêmicos da Faculdade de Medicina da Universidade de São Paulo (FMUSP), sendo consolidado a partir de 1957.

Voltada para a educação e a pesquisa de campo na área médica, a Bandeira manteve em vista a atuação dos estudantes (em média 25 por ano) em um contexto diferente daquele visto nos hospitais, por meio do contato com diferentes realidades da população brasileira.

A partir dos dados coletados durante as expedições, o projeto gerou diversos artigos para publicações científicas, principalmente nas áreas da microbiologia e da parasitologia.

1. Professor titular do Instituto de Física de São Carlos da Universidade de São Paulo, Pro-Reitor de Graduação da Universidade de São Paulo.

2. Professor titular da Faculdade de Medicina da Universidade de São Paulo, Pro-Reitor de Graduação Adjunto da Universidade de São Paulo.

Endereço para correspondência: Edmundo C. Baracat. Av. Dr. Eneás de Carvalhos Aguiar, 255 - Cerqueira Cesar. CEP: 05403900 - Sao Paulo, SP - Brasil. 
Fernandes AC, Baracat EC. ACC - Atividades acadêmicas complementares.

Em 1969, foi interrompido devido a problemas políticos entre o regime militar e a Faculdade de Medicina da USP. Trinta anos depois, em 1998, um grupo de estudantes da FMUSP encontrou arquivos referentes ao Projeto e decidiu se organizar para reativá-lo, passando à configuração de Projeto de Extensão Universitária da USP.

Com a retomada do projeto, uma nova vertente foi introduzida: o assistencialismo à população. Ao longo dos anos, cursos de outras unidades da USP foram incorporados ao Projeto, aumentando sua área de atuação e proporcionando à população atendida um cuidado mais abrangente e interdisciplinar.

As novas expedições têm sido marcadas pelo contato com a Prefeitura do Município, bem como com outros gestores, como forma de garantir a continuidade da atuação dos alunos após os dez dias de expedição.

\section{Faculdades participantes do Projeto Bandeira Científica}

- Medicina: área da Medicina atua em três grandes vertentes do projeto.

- Medicina Jr.: Empresa Júnior da Escola de Enfermagem e da Faculdade de Medicina da USP.

- Nutrição: A nutrição tem como objetivo a promoção, manutenção e recuperação da saúde.

- Odontologia: O foco principal da Odontologia é empoderar a população no que se relaciona com a prevenção das principais doenças bucais.

- Fisioterapia: O curso de Fisioterapia da Faculdade de Medicina da Universidade de São Paulo.

- Fonoaudiologia: A Fonoaudiologia é a ciência que tem a missão de estudar a voz, a fala, a audição, a escrita, a leitura e outros meios de comunicação humana.

- Psicologia: Na Bandeira Científica, a Psicologia entra a partir de uma perspectiva da Psicologia Social, na qual se entende que o contexto e o sujeito estão interligados.

- Poli (Engenharias Ambiental e Civil): A equipe composta por estudantes das Engenharias Ambiental e Civil da Escola Politécnica.

- FEA (Economia, Administração e Contabilidade): O objetivo da participação da FEA é trabalhar a inclusão socioeconômica como instrumento de melhoria do bem-estar biopsicossocial.

O Mentoring (ou tutoria em grupo) é um sistema de tutores/orientadores em que um docente é orientador de um grupo de 9 a 12 alunos, composto por alunos dos 6 anos do curso de medicina da Faculdade de Medicina da USP.

O objetivo principal é estabelecer, para cada grupo de alunos, um orientador, que acompanhará o seu progresso acadêmico e os auxiliará em problemas eventualmente surgidos no decorrer do curso. O tutor terá, também, a responsabilidade inicial de avaliar situações de alunos com problemas diversos e sugerir a eles, quando necessário, a procura de outros recursos de auxílio.

As Ligas Acadêmicas são associações estudantis que visam complementar a formação acadêmica em uma área específica do campo médico, por meio de atividades que atendam os princípios do tripé universitário de ensino, pesquisa e extensão. 